\title{
13 Raw Materials, Techniques and Sequences: Fabrics
}

The difference between paste and fabric is based on the fact that the first relate to the features of the material in its unfired state. In contrast, fabrics involve the compositional features of the material after firing. This distinction is relevant since the firing process determines, in part, the final composition of the end products. Pottery fabrics can be established through chemical, petrological, mineralogical and textural analyses of the sherds focused on the composition of the paste after the firing process. Furthermore, the establishment of fabrics permits us to know the varied products associated with an archaeological context. However, it should be stressed that there is no direct correlation between fabrics and production units. In this sense, a single production unit can produce several fabrics involving one or more vessels, while different units and even diverse production centres can manufacture the same fabric (Buxeda et al., 1995; García Rosselló, 2008; Whitbread, 1989).

The composition of one fabric (Fig. 13.1) is determined by all the actions performed by the potter along the chaîne opératoire:

- Type of raw materials selected

- Clay purification systems and tempers added

- Hydration and modelling procedures

- Drying process

- Surface treatments applied

- Temperature, atmosphere and duration of the firing process

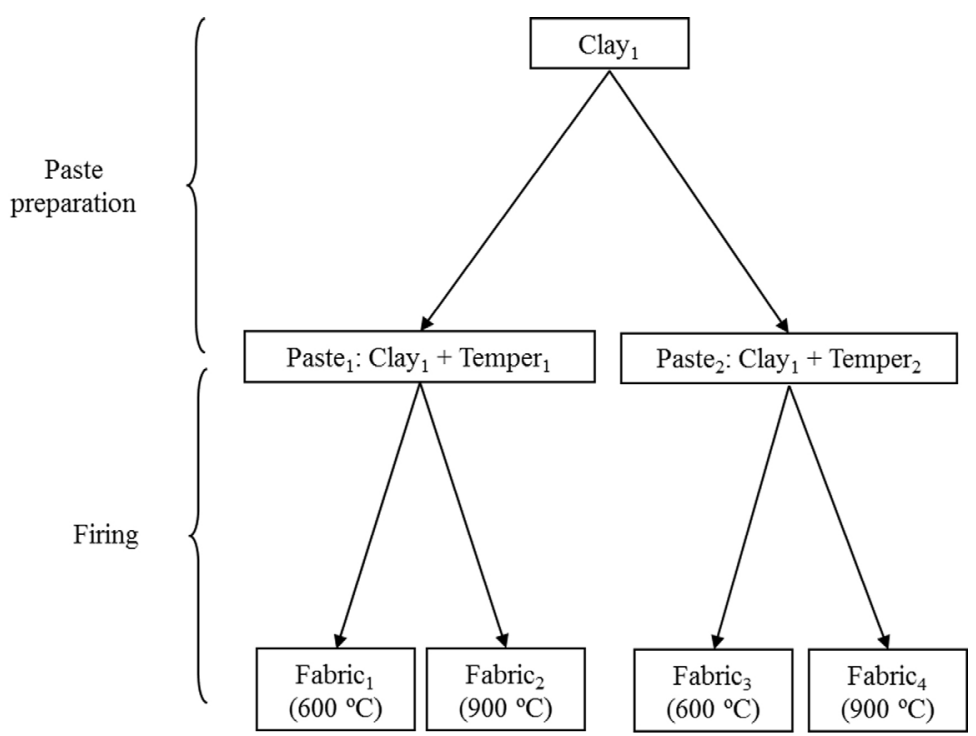

Figure 13.1: Conceptual scheme of the formation of successive fabrics from the use of different raw materials, temper and firing procedures. 
All these actions alter the raw materials and, if performed differentially, result in multiple combinations that generate different pastes and/or fabrics. The potter's actions determine, then, the properties and final characteristics of the diverse fabrics in terms of mineralogical and chemical composition, texture, porosity, consistency, hardness, weight, durability, compactness, colour, surface appearance, shape, homogeneity, symmetry of the shape, etc. The final product is therefore largely determined by the materials and techniques used in its production. These factors, which are strongly related to particular technological choices, determine in turn the physical properties of the artefacts, such as their thermal resistance or mechanical strength, as well as the way they are perceived and visualised (Capel et al., 1982; Cuomo Di Caprio, 1985; Darvill and Timby, 1982; Dietler and Herbich, 1998; MacGregor, 1999; Prieto, 1999, 2006; Whitbread, 1989).

A pottery fabric is then characterised by a particular chemical, mineralogical and textural composition that relates to both the clay matrix and the inclusions or tempers that make up the ceramic body. Thus, fabrics are established according to certain physicochemical characteristics of the pottery assemblages. In this way, vessels grouped in a particular fabric share a number of common technological features related to the use of the same or very similar materials and techniques throughout their chaîne opératoire. The interpretation of ceramic technology in cultural and social terms is based on the determination of some distinctive technological features in ceramic assemblages related to certain technological choices. The potter's choice of certain materials and techniques in the production of specific ceramics is a reflection of his/her cultural tradition. In this sense, it is essential to know the materials and techniques chosen to produce the vessels in order to establish fabrics and go further in the interpretation of the technological features of pottery assemblages. The analysis of the fabric is essential since it is the final result of all the materials and techniques used in the production of the pottery and involves an object that has its own rationale in a given society. That is the reason why it is essential to group together pottery vessels manufactured through identical technological conceptions and using raw materials with similar characteristics and properties. In this sense, the concept of fabric allows us to compare the technological features existing between different pottery assemblages, that may have been made with clays of different provenance but, nevertheless, using similar technological choices.

Furthermore, the manufacture of a particular fabric involves certain effort investment. Thus, this concept also provides information regarding pottery production in economic terms. For instance, the time and effort invested to produce the pottery can be related to the cost of the materials and the product use life. The time invested in the preparation of the paste may vary depending on the distance to the clay sources, the means used to transport the raw material, the level of purification of the clay and the time spent in searching for and preparing the temper. For instance, the time spent to prepare the paste and to form pots may differ depending on the type of temper selected. Thus, pottery may be performed in less than 30 minutes using organic 
matter as temper (Skibo et al., 1989), while it may require about 90 minutes if crushed calcite is added to the clay (Martineau et al., 2007). This viewpoint clearly responds to westerners' conceptions of technical and economic efficiency. However, analysing the effort investment devoted to each phase of the pottery production may be useful to address other aspects involved in the selection of raw materials and techniques, and thereby in obtaining particular end products (Martineau et al., 2007).

Finally, it should be noted that, as in the establishment of petrogroups, the selection of the parameters that group a pottery assemblage in a particular fabric involves some degree of subjectivity. Creating a fabric implies a process of interpretation regarding the similarities and differences existing among the vessels that is deeply influenced by the theoretical perspectives of the researchers. Hence, although fabrics represent a useful concept for approaching technology in archaeological ceramics, we have to be aware that they are created from the researchers' rationality patterns and relate to specific ways of organising and understanding the ceramic assemblage. In short, there is no perfect fabric.

In this sense, the goals, procedures and enquiries generated by researchers are significantly distanced from the context in which the ceramic was originally placed. The pottery was related to the potters' rationality patterns and, then, the aims they pursued in a given functional, social, economic, symbolic and ideological context. Thus, the same vessel could be classified in different fabrics depending on the potter's or researcher's viewpoints. Moreover, diverse researchers may even apply differing perspectives and classification criteria in the study of the same pottery assemblage. 